\title{
ENSIKLOPEDI RUMAH ADAT DI PULAU JAWA MENGGUNAKAN TEKNOLOGI AUGMENTED REALITY SEBAGAI MEDIA PEMBELAJARAN YANG INTERAKTIF
}

\author{
Wijaya Wahyudi Akbar'), Oky Dwi Nurhayati ${ }^{2)}$, Kurniawan Teguh Martono ${ }^{2}$ \\ Program Studi Sistem Komputer, Fakultas Teknik, Universitas Diponegoro \\ Jalan Prof. Sudharto, Tembalang, Semarang, Indonesia
}

\begin{abstract}
Technological advances become one of the important moments in human life, because the technology effect on all areas related to human. Both in the military, health, community services, education, and much more. Education is the key factor in the progress of a nation. Education that is integrated with the technological advances of course be one of the driving force of the nation's progress. One of them using augmented reality technology.

Applications Java Encyclopedia Traditional House is the result of the combined two essential components, namely education and technology. Using augmented reality-based technology that can facilitate learning in a familiar custom home on the island of Java. There are 6 custom homes in every province of the island of Java, namely kebaya in jakarta, kesepuhan Cirebon in West Java, East Java situbondo, Padepokan in Central Java, Badui in Banten, and Kencono Traditional House in Yogyakarta.

Applications built using the $C$ \# programming language, it is very interactive. So that users not only know the 3-dimensional shape of an existing custom home, but know many things about the area tersebut.Telah conducted testing of these applications, functionally works well and reading the marker successfully.
\end{abstract}

Index Terms : education, augmented reality, $c$ \#, markers, traditional house

\section{Pendahuluan}

\subsection{Latar Belakang}

Menurut Prihantono (2013), pesatnya perkembangan teknologi semakin berpengaruh pada segala bidang, seperti bidang edukasi, hiburan, militer, kesehatan, dan lain sebagainya. Dunia edukasi adalah dunia yang cakupannya meliputi seluruh belahan dunia, tak terbatas pada cakupan sebuah daerah. Salah satu contohnya seperti sejarah yang terjadi pada sebuah Negara bisa saja dipelajari oleh Masyarakat di Negara yang berbeda. Oleh karena itu perkembangan pola pembelajaran terutama ilmu mengenai Perkembangan Teknologi Informasi (TIK) di bidang edukasi sangat berpengaruh terhadap model dan pola pengajaran yang ada saat ini.
Dengan melatarbelakangi pentingnya mempelajari budaya sebuah bangsa, khususnya budaya Indonesia yang sangat menarik karena terdiri dari ribuan suku dan adat. Maka dari ini mencoba mengkolaborasikan budaya Indonesia dengan perkembangan teknologi informasi dalam bidang multimedia yaitu Augmented Reality dalam sebuah aplikasi interaktif yang bisa dijadikan sebagai media pembelajaran. Adapun materi yang akan dijadikan sebagai objek pembelajaran yaitu budaya Indonesia khususnya rumah adat yang menjadi identitas sebuah daerah. Materi ini sangat tepat dijadikan sebagai objek pembelajaran karena pelajar susah untuk melihat secara langsung seluruh rumah adat di Indonesia mengingat jaraknya yang jauh satu sama lain. Selain itu juga pelajar dapat mempelajari dan mengerti sejarah singkat dan ciri khas dari setiap rumah adat tersebut.

\subsection{Tujuan}

Tujuan dari Tugas Akhir ini adalah:

Menghasilkan sebuah aplikasi berbasis Augmented Reality mengenai budaya Indonesia khususnya rumah adat di Pulau Jawa yang bersifat interaktif dan menghibur.

\subsection{Batasan Masalah}

Agar tidak menyimpang dari permasalah, Tugas Akhir ini memiliki batasan masalah sebagai berikut.

1. Aplikasi ini dikembangkan pada Android.

2. Aplikasi ini dikembangkan menggunakan software Vuforia.

3. Produk ini bersifat beta yang belum bisa digunakan secara umum.

4. Terdapat 6 rumah adat yang ada di Pulau Jawa yaitu di Daerah Jakarta, Banten, Jawa Tengah, Jawa Barat, Jawa Timur, dan Yogyakarta.

\section{LANDASAN TEORI}

\subsection{Multimedia}

Pada awalnya multimedia hanya mencakup media yang menjadi konsumsi indra penglihatan (gambar diam, teks, gambar gerak video, dan gambar gerak rekaan/animasi), dan konsumsi indra pendengaran (suara) dan juga berupa (berwujud). Dalam perkembangannya multimedia mencakup juga kinetik (gerak) dan bau yang merupakan konsumsi indra penciuman. Multimedia mulai 
memasukkan unsur kinetik sejak diaplikasikan pada pertunjukan film 3 dimensi yang digabungkan dengan gerakan pada kursi tempat duduk penonton. Kinetik dan film 3 dimensi membangkitkan sense realistis.

\subsection{Augmented Reality}

Suryawinata (2010), Augmented Reality (AR) adalah kombinasi antara dunia maya (virtual) dan dunia nyata (real) yang dibuat oleh komputer. Objek virtual dapat berupa teks, animasi, model 3D atau video yang digabungkan dengan lingkungan sebenarnya sehingga pengguna merasakan objek vitual berada dalam lingkungannya. AR adalah cara baru dan menyenangkan dimana manusia berinteraksi dengan komputer, karena dapat membawa objek virtual ke lingkungan pengguna, memberikan pengalaman visualisasi yang alami dan menyenangkan. Sistem ini berbeda dengan virtual reality (VR), yang sepenuhnya merupakan virtual environment. Hasilnya ditampilkan secara interaktif dan dalam waktu nyata (realtime). Terdapat integrasi antarbenda dalam tiga dimensi, yaitu benda maya terintegrasi dalam dunia nyata.

\subsection{Vuforia}

Menurut Mario (2013) Vuforia merupakan software untuk Augmented Reality yang dikembangkan oleh Qualcomm, mengenai visi komputer yang berfokus pada pengenalan gambar. Vuforia mempunyai banyak fiturfitur dan kemampuan, yang dapat membantu pengembangan untuk mewujudkan pemikiran tanpa batas secara teknikal.

Dengan support untuk iOS, Android, dan Unity3D, platform Vuforia mendukung para pengebangan untuk membuat aplikasi yang dapat digunakan di hampir seluruh jenis smartphone dan tablet.

\subsection{Android}

Menurut situs Kessler (2010) Android adalah sistem operasi untuk telepon seluler berbasis Linux. Android menyediakan platform terbuka bagi pengembang untuk menciptakan aplikasi mereka sendiri digunakan oleh bermacam perangkat bergerak. Awalnya, Google Inc. Membeli Android Inc., pendatang baru yang membuat piranti lunak untuk ponsel. Kemudaian untuk mengambangkan Android, dibentuklah Open Handset Alliance, konsorsium dari 34 perusahaan peranti keras, peranti lunak, dan telekomunikasi, termaksud Google, HTC, Intel, Motorola, Qualcomm, T-Mobile, dan Nvidia.

Terdapat beberapa versi pada sistem operasi Android, mulai dari vrsi 1.5 (Cup Cake), versi 1.6 (Donut), versi 2.1 (Eclair), versi 2.2 (Froyo), versi 2.3 (GingerBread), versi 3.0 (HoneyComb), versi 4.0 (Ice Cream Sandwich), Jely Bean dan yang versi terbaru KitKat.

\subsection{D Max}

Menurut Hendratman (2012) 3D Studio Max adalah software visualisasi (modelling dan animasi) Tiga Dimensi yang populer dan serbaguna. Hasilnya yang dibuat di 3D Studio Max sering digunakan di pertelevisian, Media Cetak, Games, Web, dan lain-lain. Aplikasi ini yang digunakan untuk membuat design rumah adat.

\subsection{Unity}

Menurut Rickman (2014) Unity Technology dibangun pada tahun 2014 oleh David Helgason, Nicholas Francis dan Joachim Ante. Game engine dibangun atas kepedulian mereka terhadap indie developer developer yang tidak bisa membeli game engine karena terlalu mahal. Fokus perusahaan ini adalah membuat sebuah perangkat lunak yang bisa digunakan oleh semua orang, khususnya untuk membangun sebuah game. Di tahun 2009, Unity diluncurkan secara gratis dan di bulan april 2012, Unity mencapai popularitas tertinggi dengan lebih dari 1 juta developer terdaftar di seluruh dunia. Unity dapat membuat sebuah game 3D dengan mudah dan cepat. Secara default, Unity telah diatur untuk pembuatan game bergenre First Person Shooting (FPS), namun Unity juga bisa digunakan untuk membuat game bergenre Role Playing Game (RPG), dan Real Time Strategy (RTS). Selain itu Unity merupakan sebuah engine multiplatform yang memungkinkan game di-publish untuk berbagai platform seperti Windows, Mac, Android, IoS, PS3 dan juga Wii.

\subsection{Rumah Adat}

Pulau jawa terdiri dari 6 Provinsi yaitu Banten, DKI Jakarta, Jawa Barat, Jawa Tengah, Jawa Timur dan DIY Yogyakarta. Setiap provinsi yang ada memili ciri khan seperti makanan dan minuman, bahasa, pakaian dan rumah yang disebut dengan rumah adat. Dan berdasarkan judul tugas akhir, akan dijelaskan satu per satu rumah adat beserta ciri khanya yang ada di pulau Jawa.

\section{Perancangan Sistem}

Secara garis besar metode Waterfall mempunyai langkah-langkah sebagai berikut: Analisa, Desain, Penulisan, Pengujian dan Penerapan serta Pemeliharaan. Dan adapun tahapan perancangan menggunakan Metode Waterfall antara lain:

Langkah ini merupakan analisa terhadap kebutuhan system. Sistem analis akan menggali informasi sebanyakbanyaknya dari pengguna sehingga akan tercipta sebuah sistem komputer yang bisa melakukan tugas-tugas yang diinginkan oleh pengguna tersebut. Tahapan ini akan menghasilkan dokumen pengguna requirment atau bisa dikatakan sebagai data yang berhubungan dengan keinginan pengguna dalam pembuatan sistem. Dokumen ini lah yang akan menjadi acuan sistem analis untuk menerjemahkan ke dalam bahasa pemrogram.

\subsection{Diagram Blok}

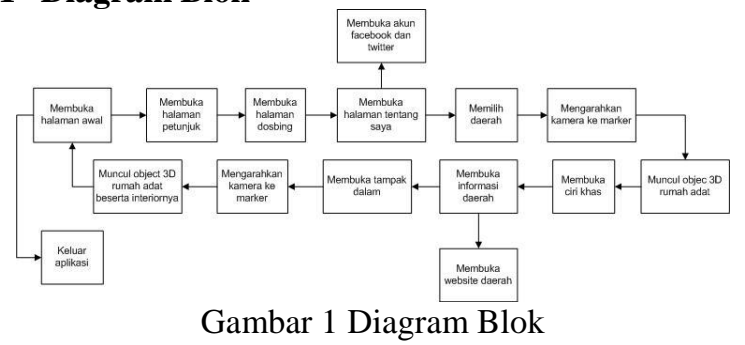


Pada Gambar 1 dapat diketahui bahwa pengguna memiliki peran sebagai pengontrol jalannya aplikasi Ensiklopedi Augmented Reality. Dalam aplikasi ini hanya ada satu pangguna. Karena sifat dari aplikasi ini stand alone dimana tidak ada interaksi client server sehingga dalam proses menjalankannya hanya membutuhkan satu pengguna saja.

\subsection{Use Case}

Fungsi yang harus dipenuhi dalam aplikasi permainan didefinisikan melalui use case. Diagram use case aplikasi pada Gambar 2 .

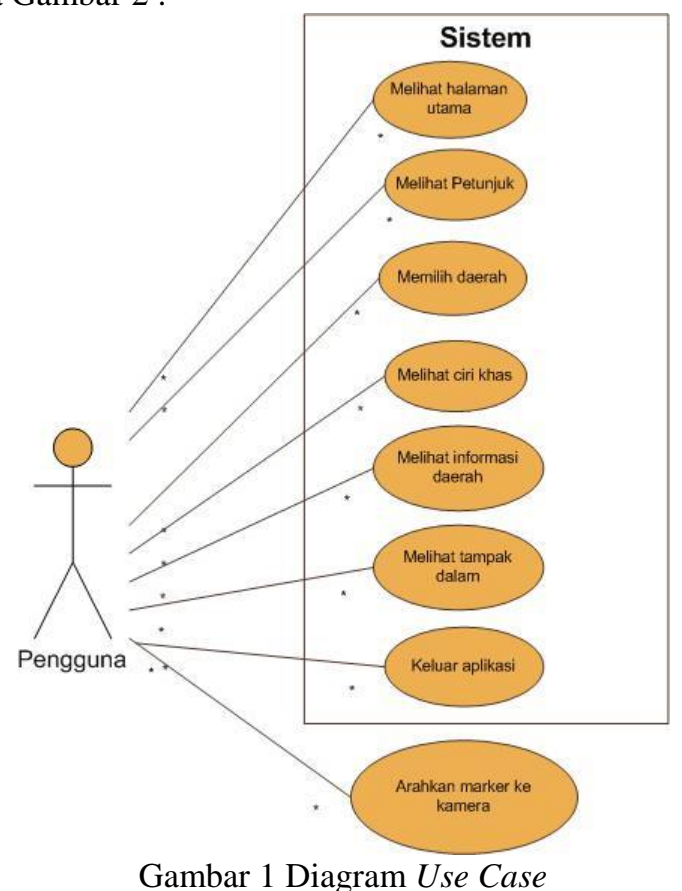

\subsection{Sekuens}

Terdapat beberapa diagram sekuens pada aplikasi ini. Antara lain:

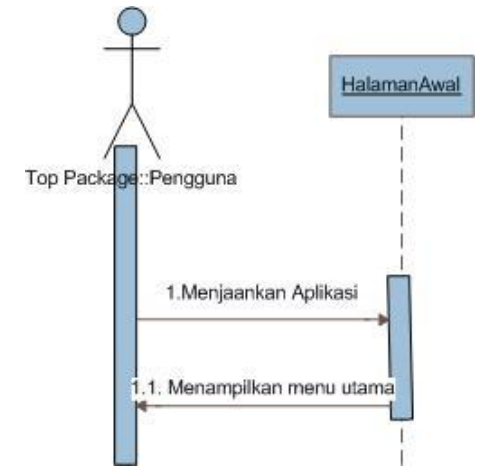

Gambar 2 Sekuens Halaman Utama

Gambar 3 menjelaskan bahwa pengguna menjalankan aplikasi Ensiklopedi pada layar mobile device. Dan sistem akan memberikan respon berupa tampilan halaman utama dari aplikasi. Pada tahapan ini, scene pada halaman utama adalah 1.Home. Yang kemudian pada halaman utama ini terdapat beberapa button yang dapat diakses.

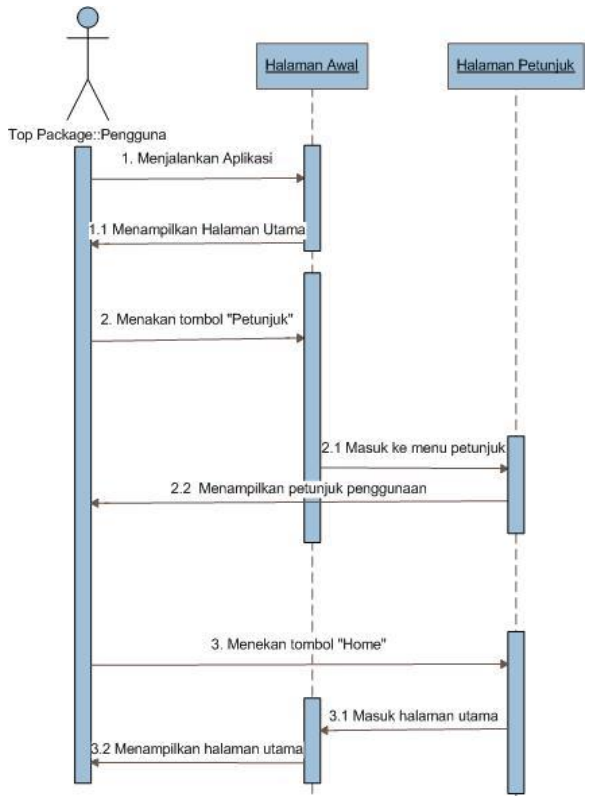

Gambar 4 Sekuens Halaman Petunjuk

Gambar 4 menjelaskan bahwa pengguna menjalankan aplikasi Ensiklopedi pada layar mobile device. Dan sistem akan memberikan respon berupa tampilan halaman utama dari aplikasi. Kemudian pengguna menekan tombol "Petunjuk" dan akan memanggil kelas GantiScene dan method ChangeToScene() untuk memanggil scene 1.Home_Petunjuk, dan sistem akan menampilkan halaman petunjuk. Kemudian pengguna menekan tombol "home" pada halaman petunjuk untuk kembali ke halaman utama aplikasi dengan kelas GantiScene dan method ChangeToScene() untuk memanggil scene 1.Home. Dan sistem akan menampilkan halaman utama.

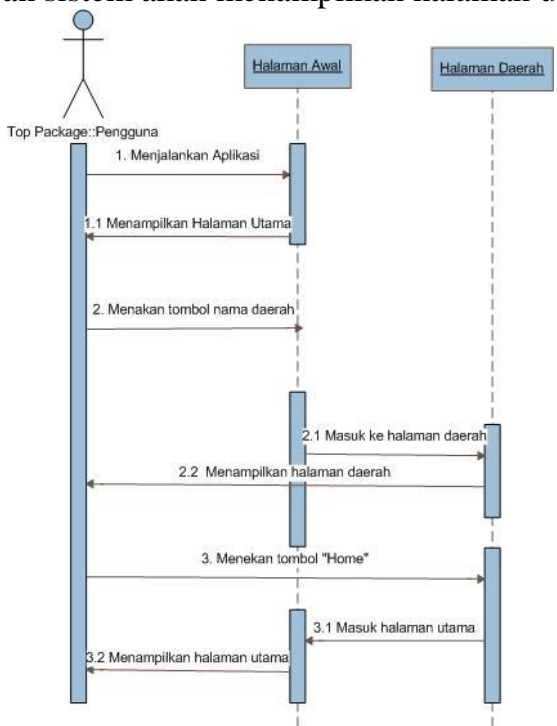

Gambar 5 Sekuens Halaman Daerah

Gambar 5 menjelaskan bahwa pengguna menjalankan aplikasi Ensiklopedi pada layar mobile device. Dan sistem akan memberikan respon berupa tampilan halaman utama dari aplikasi. Kemudian pengguna menekan tombol nama daerah pada peta pulau Jawa dan akan memanggil kelas GantiScene dan method ChangeToScene() untuk memanggil scene daerah. Dan sistem akan menampilkan halaman utama daerah. Kemudian pengguna menekan 
tombol "home" pada halaman petunjuk untuk kembali ke halaman utama aplikasi dengan kelas Gantiscene dan method ChangeToScene() untuk memanggil scene 1.Home. Dan sistem akan menampilkan halaman utama.

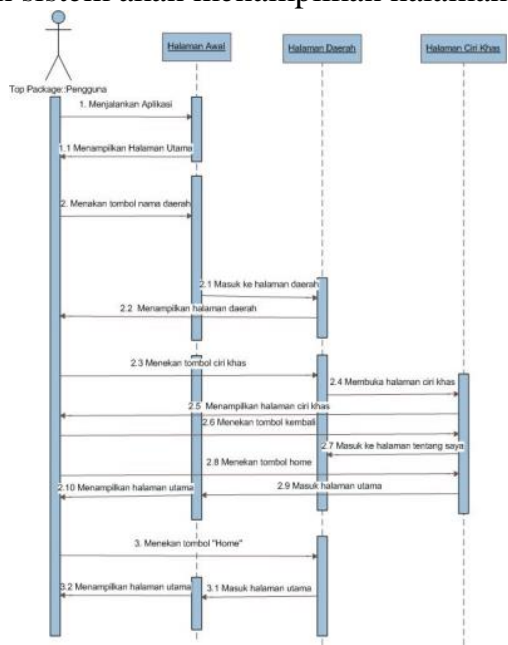

Gambar 6 Sekuens Ciri Khas

Gambar 6 menjelaskan bahwa pengguna menjalankan aplikasi Ensiklopedi pada layar mobile device. Dan sistem akan memberikan respon berupa tampilan halaman utama dari aplikasi. Kemudian pengguna menekan tombol nama daerah pada peta pulau Jawa dan akan memanggil kelas GantiScene dan method ChangeToScene() untuk memanggil scene ciri khas. Dan sistem akan menampilkan halaman utama ciri khas dari rumah adat. Pengguna menekan tombol "back" pada halaman ciri khas untuk kembali ke halaman utama rumah adat dengan kelas Gantiscene dan method ChangeToScene () untuk memanggil scene halaman utama rumah adat. Dan sistem akan menampilkan halaman utama rumah adat. Kemudian pengguna menekan tombol "home" pada halaman petunjuk untuk kembali ke halaman utama aplikasi dengan kelas Gantiscene dan method ChangeToScene () untuk memanggil scene 1.Home. Dan sistem akan menampilkan halaman utama.

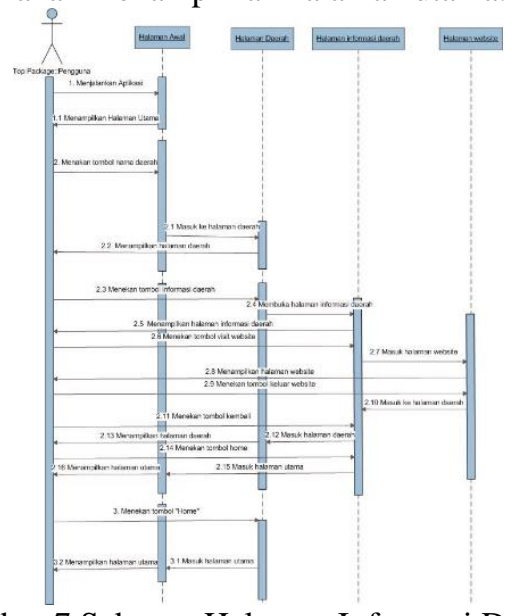

Gambar 7 Sekuens Halaman Informasi Daerah

Gambar 7 menjelaskan bahwa pengguna menjalankan aplikasi Ensiklopedi pada layar mobile device. Dan sistem akan memberikan respon berupa tampilan halaman utama dari aplikasi. Kemudian pengguna menekan tombol nama daerah pada peta pulau Jawa dan akan memanggil kelas
GantiScene dan method ChangeToScene() untuk memanggil scene daerah. Kemudian pengguna pada halaman utama daerah menekan tombol informasi daerah dengan method ChangeToScene(). Dan sistem akan menampilkan informasi daerah. Pengguna menekan tombol "visit website" dengan kelas URLJogja dan method OpenURL(), kemudian sistem akan membuka website dan menampilkan informasi yang lain mengenai daerah. Lalu pengguna keluar dari website dan sistem akan menampilkan halaman infrormasi daerah. Pengguna menekan tombol "back" pada halaman informasi daerah untuk kembali ke halaman utama rumah adat dengan kelas GantiScene dan method ChangeToScene() untuk memanggil scene halaman utama rumah adat. Dan sistem akan menampilkan halaman utama rumah adat. Kemudian pengguna menekan tombol "home" pada halaman petunjuk untuk kembali ke halaman utama aplikasi dengan kelas GantiScene dan method ChangeToScene () untuk memanggil scene 1.Home. Dan sistem akan menampilkan halaman utama.

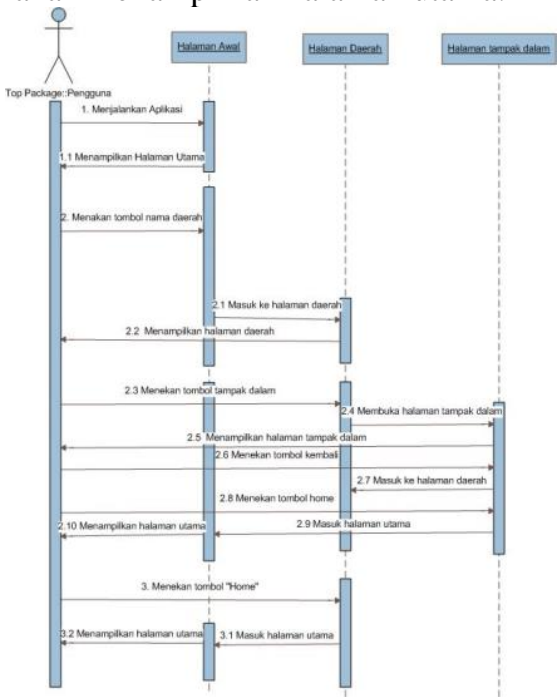

Gambar 8 Sekuens Halaman Tampak Dalam

Gambar 8 menjelaskan bahwa pengguna menjalankan aplikasi Ensiklopedi pada layar mobile device. Dan sistem akan memberikan respon berupa tampilan halaman utama dari aplikasi. Kemudian pengguna menekan tombol nama daerah pada peta pulau Jawa dan akan memanggil kelas GantiScene dan method ChangeToScene() untuk memanggil scene nama daerah. Dan sistem akan menampilkan halaman utama daerah. Dan pengguna menekan tombol "tampak dalam" pada halaman utama dengan method ChangeToScene() dan sistem akan menampilkan halaman AR tampak dalam. Pengguna menekan tombol "back" pada halaman tampak dalam untuk kembali ke halaman utama rumah adat dengan kelas GantiScene dan method ChangeToScene() untuk memanggil scene halaman utama rumah adat. Dan sistem akan menampilkan halaman utama rumah adat. Kemudian pengguna menekan tombol "home" pada halaman petunjuk untuk kembali ke halaman utama aplikasi dengan kelas Gantiscene dan method ChangeToScene() untuk memanggil scene 1.Home. Dan sistem akan menampilkan halaman utama. 


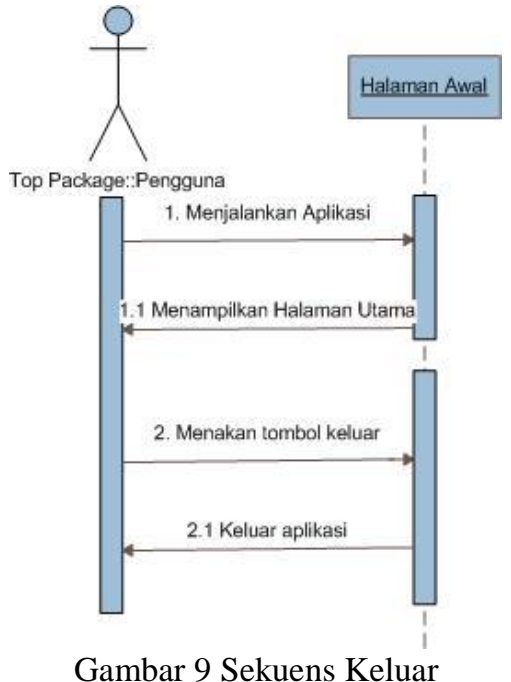

Gambar 9 Sekuens Keluar

Gambar 9 menjelaskan bahwa pengguna menjalankan aplikasi Ensiklopedi pada layar mobile device. Dan sistem akan memberikan respon berupa tampilan halaman utama dari aplikasi. Kemudian pengguna menekan tombol "Keluar" dan akan memanggil kelas quit dan method Keluar () dan sistem akan memberhentikan aplikasi dan keluar dari aplikasi.

\subsection{Kelas Diagram}

Proses yang terjadi pada setiap ativitas dalam aplikasi merupakan interaksi suatu objek dengan objek lainnya. Interaksi yang terjadi merupakan proses mengirim dan menerima pesan agar suatu objek melakukan suatu aktivitas sesuai perintah yang diberikan pengguna. Hubungan antarkelas ditunjukkan pada diagram kelas sesuai Gambar 10

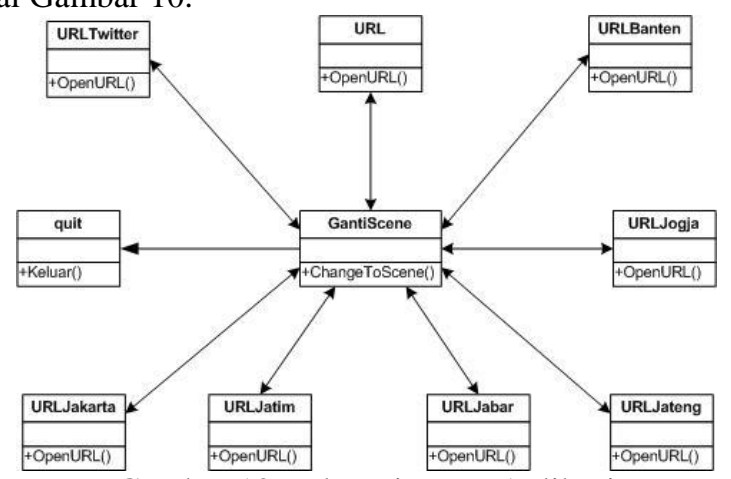

Gambar 10 Kelas Diagram Aplikasi

Pada aplikasi ini, kelas utama dari aplikasi adalah Gantiscene yang mempunyai method ChangeToScene (). Dapat dihubungkan dengan kelas yang ada seperti ada gambar di atas.

\section{IMPLEMENTASI DAN PENGUJIAN}

\subsection{Implementasi}

Buat scene sesuai rumah adat yang ada, seperti 2.Yogja_CiriKhas agar dapat dengan mudah dipanggil oleh script GantiScene.cs. Dan antarmuka halaman ciri khas seperti pada Gambar 11.

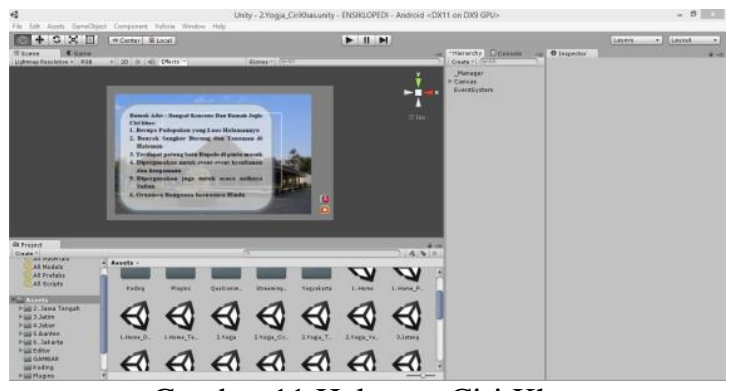

Gambar 11 Halaman Ciri Khas

Halaman ini akan memberikan informasi lebih lanjut mengenai daerah yang sedang dipelajari. Dengan menekan button yang berlabel nama daerah pada halaman utama rumah adat, maka akan membuka halaman ini. Halaman ini dapat diberi nama seperti 2.Jogja_Yogjakarta dan mempunyai tampilan antarmuka seperti pada Gambar 12 .

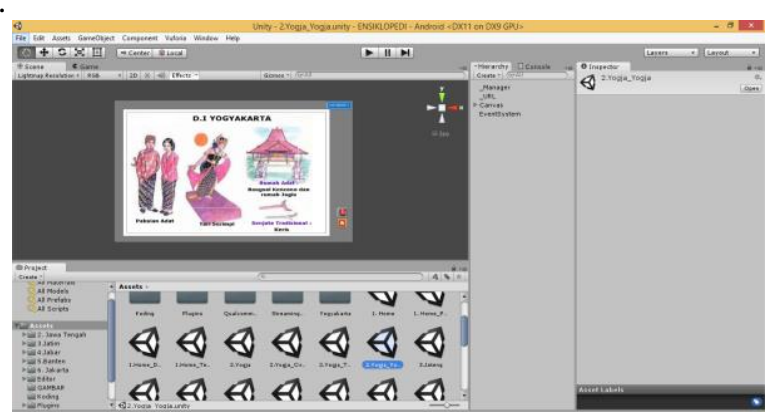

Gambar 12 Halaman Informasi Daerah

Pada halaman ini menggunakan AR Camera, yang dimana ketika kamera diarahkan pada marker akan keluar 3D objek rumah adat tanpa menggunakan atap. Sehingga akan terlihat lebih jelas interior bangunan yang ada di dalamnya. Tampilan salah satu rumah adat seperti pada Gambar 13.

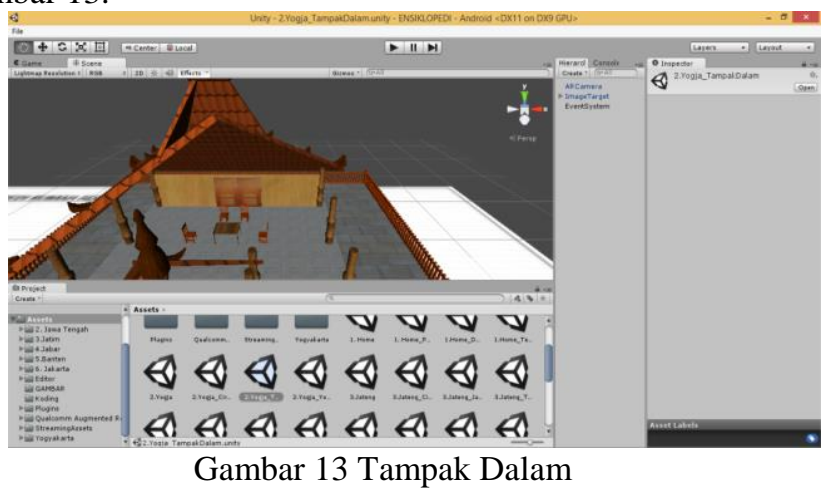

\subsection{Pengujian Aplikasi}

Pengujian digunakan untuk memastikan aplikasi dapat berjalan dengan lancar dan sesuai dengan. Pengujian fungsional program dilakukan untuk mengetahui apakah fungsi yang dispesifikasikan dalam perancangan permainan dapat berjalan dengan baik. Fungsi yang diuji dan hasil pengujian ditunjukkan pada Tabel 1 .

Tabel 1 Pengujian

\begin{tabular}{|r|c|l|l|c|}
\hline No. & Fungsi & $\begin{array}{c}\text { Kondisi } \\
\text { Awal }\end{array}$ & Kondisi Akhir & Hasil \\
\hline 1. & $\begin{array}{l}\text { Memulai } \\
\text { halaman } \\
\text { utama }\end{array}$ & $\begin{array}{l}\text { Pengguna } \\
\text { belum } \\
\text { membuka }\end{array}$ & $\begin{array}{l}\text { Sistem } \\
\text { menampilkan } \\
\text { halaman uama }\end{array}$ & Berhasil \\
\hline
\end{tabular}




\begin{tabular}{|c|c|c|c|c|}
\hline & & aplikasi & aplikasi & \\
\hline 2. & $\begin{array}{l}\text { Melihat } \\
\text { petunjuk }\end{array}$ & $\begin{array}{l}\text { Pengguna } \\
\text { berada di } \\
\text { halaman } \\
\text { utama } \\
\text { aplikasi }\end{array}$ & $\begin{array}{l}\text { Sistem } \\
\text { menampilkan } \\
\text { halaman } \\
\text { petunjuk dan } \\
\text { kembali ke } \\
\text { halaman } \\
\text { utama }\end{array}$ & Berhasil \\
\hline 3. & $\begin{array}{l}\text { Memilih } \\
\text { daerah }\end{array}$ & $\begin{array}{l}\text { Pengguna } \\
\text { berada di } \\
\text { halaman } \\
\text { utama } \\
\text { aplikasi }\end{array}$ & $\begin{array}{l}\text { Sistem } \\
\text { menampilkan } \\
\text { halaman } \\
\text { utama daerah }\end{array}$ & Berhasil \\
\hline 4. & $\begin{array}{l}\text { Melihat } \\
\text { ciri khas }\end{array}$ & $\begin{array}{l}\text { Pengguna } \\
\text { berada di } \\
\text { halaman } \\
\text { utama } \\
\text { daerah }\end{array}$ & $\begin{array}{l}\text { Sistem } \\
\text { menampilkan } \\
\text { halaman ciri } \\
\text { khas rumah } \\
\text { adat }\end{array}$ & Berhasil \\
\hline 5. & $\begin{array}{l}\text { Melihat } \\
\text { informasi } \\
\text { daerah }\end{array}$ & $\begin{array}{l}\text { Pengguna } \\
\text { berada di } \\
\text { halaman } \\
\text { utama } \\
\text { daerah }\end{array}$ & $\begin{array}{l}\text { Sistem } \\
\text { menampilkan } \\
\text { halaman area } \\
\text { kota yang } \\
\text { dipilih }\end{array}$ & Berhasil \\
\hline 7. & $\begin{array}{l}\text { Melihat } \\
\text { tampak } \\
\text { dalam }\end{array}$ & $\begin{array}{l}\text { Pengguna } \\
\text { berada di } \\
\text { halaman } \\
\text { utama } \\
\text { daerah }\end{array}$ & $\begin{array}{l}\text { Sistem } \\
\text { menampilkan } \\
\text { halaman } \\
\text { tampak dalam }\end{array}$ & Berhasil \\
\hline 8. & $\begin{array}{l}\text { Keluar } \\
\text { aplikasi }\end{array}$ & $\begin{array}{l}\text { Pengguna } \\
\text { berada di } \\
\text { halaman } \\
\text { utama }\end{array}$ & $\begin{array}{l}\text { Keluar dari } \\
\text { aplikasi }\end{array}$ & Berhasil \\
\hline
\end{tabular}

\begin{tabular}{|c|c|c|c|c|c|}
\hline & 50 & 0 & 6 & $\frac{0}{6} \times 100 \%$ & $0 \%$ \\
\hline & 60 & 0 & 6 & $\frac{0}{6} \times 100 \%$ & $0 \%$ \\
\hline \multirow{6}{*}{$60^{\circ}$} & 10 & 6 & 0 & $\frac{6}{6} \times 100 \%$ & $100 \%$ \\
\hline & 20 & 6 & 0 & $\frac{6}{6} \times 100 \%$ & $100 \%$ \\
\hline & 30 & 6 & 0 & $\frac{6}{6} \times 100 \%$ & $100 \%$ \\
\hline & 40 & 6 & 0 & $\frac{6}{6} \times 100 \%$ & $100 \%$ \\
\hline & 50 & 0 & 6 & $\frac{0}{6} \times 100 \%$ & $0 \%$ \\
\hline & 60 & 0 & 6 & $\frac{0}{6} \times 100 \%$ & $0 \%$ \\
\hline \multirow{6}{*}{$90^{\circ}$} & 10 & 6 & 0 & $\frac{6}{6} \times 100 \%$ & $100 \%$ \\
\hline & 20 & 6 & 0 & $\frac{6}{6} \times 100 \%$ & $100 \%$ \\
\hline & 30 & 6 & 0 & $\frac{6}{6} \times 100 \%$ & $100 \%$ \\
\hline & 40 & 6 & 0 & $\frac{6}{6} \times 100 \%$ & $100 \%$ \\
\hline & 50 & 6 & 0 & $\frac{6}{6} \times 100 \%$ & $100 \%$ \\
\hline & 60 & 6 & 0 & $\frac{6}{6} \times 100 \%$ & $100 \%$ \\
\hline
\end{tabular}

\section{Menampilkan Halaman Awal Aplikasi}

Tabel 2 merupakan menunjukkan keberhasilan pengujian terhadap jarak dan sudut.

Tabel 2 Pengujian terhadap jarak dan sudut

\begin{tabular}{|c|c|c|c|c|c|}
\hline \multirow[b]{2}{*}{ Sudut } & \multirow{2}{*}{$\begin{array}{l}\text { Jarak } \\
(\mathrm{Cm})\end{array}$} & \multicolumn{2}{|c|}{ Keterangan } & \multirow[b]{2}{*}{ Prosentase } & \multirow{2}{*}{$\begin{array}{c}\text { Hasil } \\
\text { Prosenta } \\
\text { se }\end{array}$} \\
\hline & & $\begin{array}{c}\text { Berha } \\
\text { sil }\end{array}$ & $\begin{array}{c}\text { Gag } \\
\text { al }\end{array}$ & & \\
\hline \multirow{6}{*}{$0^{\mathrm{o}}$} & 10 & 0 & 6 & $\frac{0}{6} \times 100 \%$ & $0 \%$ \\
\hline & 20 & 0 & 6 & $\frac{0}{6} \times 100 \%$ & $0 \%$ \\
\hline & 30 & 0 & 6 & $\frac{0}{6} \times 100 \%$ & $0 \%$ \\
\hline & 40 & 0 & 6 & $\frac{0}{6} \times 100 \%$ & $0 \%$ \\
\hline & 50 & 0 & 6 & $\frac{0}{6} \times 100 \%$ & $0 \%$ \\
\hline & 60 & 0 & 6 & $\frac{0}{6} \times 100 \%$ & $0 \%$ \\
\hline \multirow{4}{*}{$30^{\circ}$} & 10 & 0 & 6 & $\frac{0}{6} \times 100 \%$ & $0 \%$ \\
\hline & 20 & 6 & 0 & $\frac{6}{6} \times 100 \%$ & $100 \%$ \\
\hline & 30 & 6 & 0 & $\frac{6}{6} \times 100 \%$ & $100 \%$ \\
\hline & 40 & 6 & 0 & $\frac{6}{6} \times 100 \%$ & $100 \%$ \\
\hline
\end{tabular}

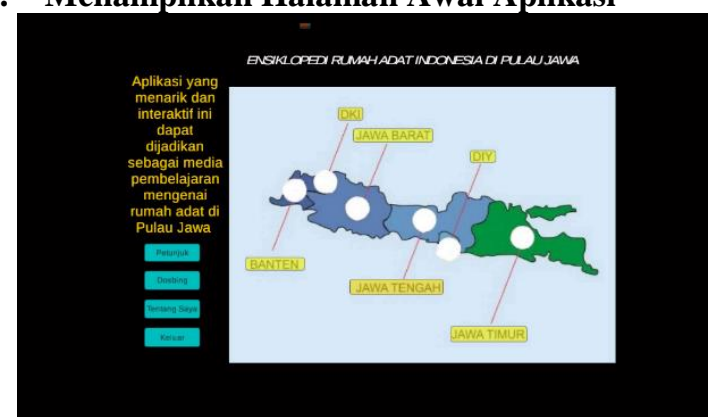

Gambar 14 Halaman Awal

Pada Gambar 4.13 merupakan tampilan halaman utama aplikasi atau yang bisa disebut dengan Home.

2. Menampilkan Halaman Petunjuk

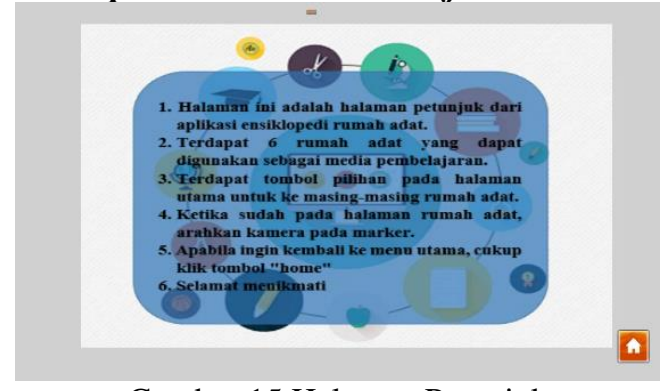

Gambar 15 Halaman Petunjuk

Pada Gambar 15 merupakan halaman petunjuk dapat di akses dan button dapat berfungsi dengan baik. 


\section{Fungsi Keluar}

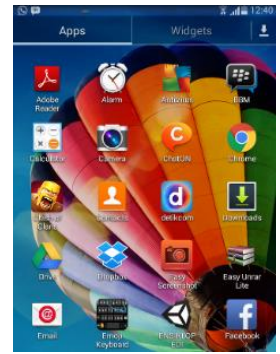

Gambar 16 Tampilan Device

Pada Gambar 16 menunjukkan bahwa fungsi button keluar berjalan dengan baik.

4. Membuka halaman utama daerah Yogjakarta

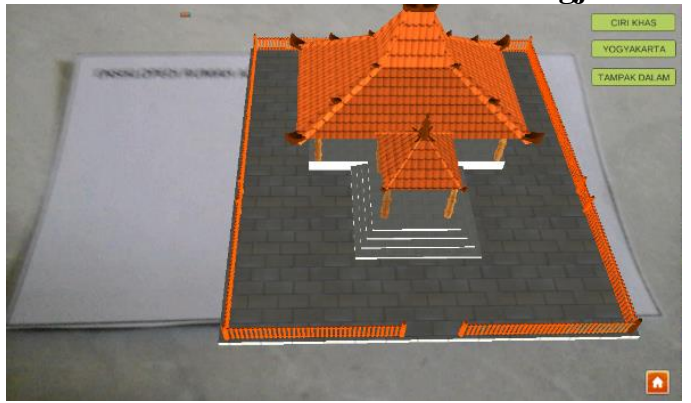

Gambar 17 Halaman Utama Daerah

Pada Gambar 17, menunjukkan bahwa halaman Yogjakarta dapat diakses dan objek 3D rumah adat Yogjakarta dapat terbaca.

\section{Halaman Ciri Khas Yogjakarta}

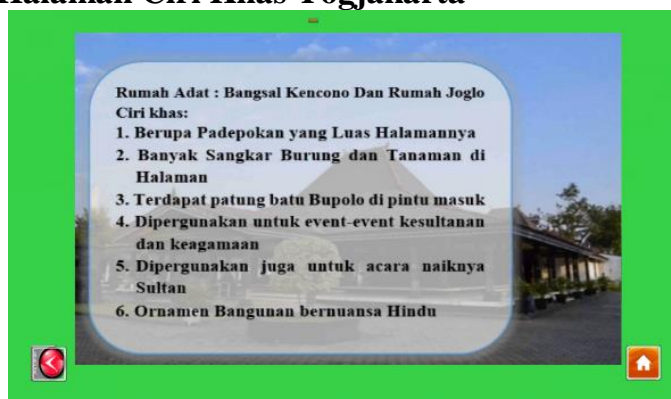

Gambar 18 Ciri Khas

Pada Gambar 18, menunjukkan bahwa halaman ciri khas dapat diakses dan button berfungsi dengan baik.

\section{Halaman Info Daerah}

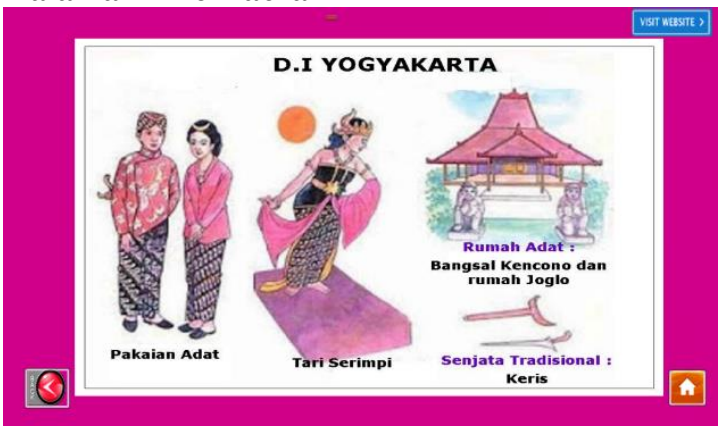

Gambar 19 Info Daerah

Pada Gambar 4.22, menunjukkan bahwan halaman info lebih mengenai daerah dapat diakses dan button berfungsi dengan baik.

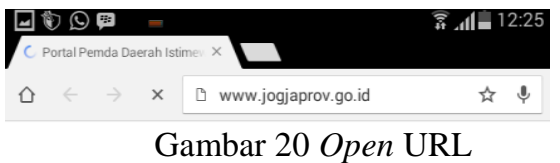

Gambar 20, menujukan bahwa button "Visit Website" dapat berfungsi dengan baik.

\section{Tampak Dalam}

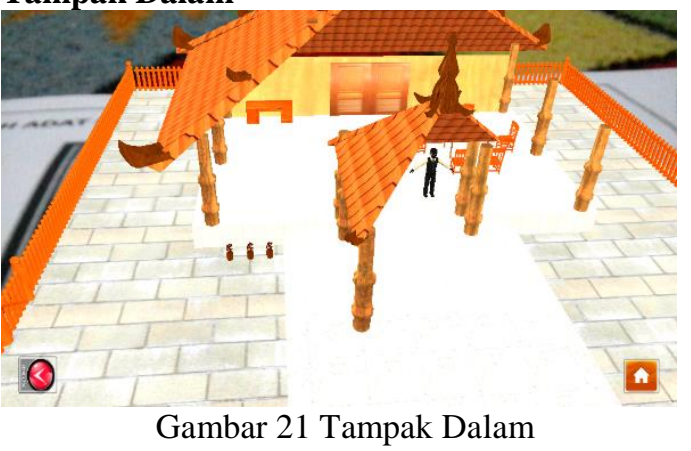

Gambar 21, menunjukkan bahwa halaman tampak dalam dapat diakses dan button berfungsi dengan baik.

\section{Penutup}

\subsection{Kesimpulan}

Berdasarkan hasil analisa dan pengujian pada aplikasi AR Ensiklopedi ini, maka dapat diambil kesimpulan sebagai berikut:

1. Seluruh URL Website dapat terbuka sehingga dapat memberikan informasi lebih.

2. Dalam penggunaan aplikasi harus diperhatikan jarak dan sudut kamera dengan marker.

3. Berdasarkan pengujian marker terhadap jarak dan posisi kamera. Sudut 0o merupakan sudut kamera tidak bisa membaca marker dan menampilkan objek 3D rumah adat pada jarak 10-60 Cm. Sedangkan pada sudut 90o, kamera dapat membaca marker dan menampilkan objek 3D dengan jarak ukur 10-60 cm. Sedangkan pada sudut $30 \mathrm{o}$, dan $60 \mathrm{o}$ marker dapat terbaca pada jarak tertentu.

4. Berdasarkan pengujian terhadap aplikasi, seluruh marker dapat terbaca dan menampilkan 3 dimensi rumah adat, seluruh button berfungsi dengan baik, dan seluruh halaman dapat terbuka

\subsection{Saran}

Dalam pengembangan aplikasi AR Ensiklopedi ini masih banyak terdapat kekurangan, maka dari itu perlu banyak pembenahan yang harus dilakukan pada pengembangan selanjutnya. Beberapa hal yang disarankan yaitu :

1. Interface aplikasi yang lebih berwarna dan menarik.

2. Memberikan efek suara pada saat berada di halaman rumah adat, seperti lagu daerah masingmasing.

3. Akses halaman AR setiap daerah lebih cepat. 